\section{Reflexão crítica sobre a invisibilidade da biossegurança e da biosseguridade}

Critical reflection on the invisibility of biosafety and biosecurity

Lia Giraldo da Silva Augusto ${ }^{1}$

\section{Introdução}

Gostaria de destacar no artigo em debate a sua atualidade e a perspectiva de não redução da biossegurança a procedimentos de avaliação de risco, ampliando-a para um escopo que inclui sua contextualização fundamental para atitudes precaucionárias tanto no nível individual, como no social e no institucional.

As autoras iniciam seu artigo conceituando o campo da biossegurança. Faz um contraponto ao conceito inglês de biossegurança centrado em procedimentos para controle de riscos especialmente no ambiente de laboratório, apresenta o desafio diante da ampliação e da intensificação das situações de riscos frente ao desenvolvimento das biotecnologias e de outras que penetram os corpos vivos, as mentes humanas e a sociedade, afetando assim, em profundidade, suas três ecologias, como nos apresenta Félix Guattari ${ }^{1}$.

\section{Os desafios contemporâneos}

A realidade humana ganhou mais complexidade em decorrência das revoluções científico-tecnológicas, que são atravessadas por grandes interesses econômicos, especialmente no mundo globalizado, onde os espaços e os tempos se estreitam, colocando paradoxalmente a sociedade do conhecimento como uma sociedade de risco.

A ampliação do conceito de biossegurança e biosseguridade, apresentando-as como campos de inter-relações entre as situações de riscos tecnológicos, à saúde humana e ao ambiente, bem como a incorporação da bioproteção e da bioética, possibilitam o enfrentamento dos pares dialéticos "visibilidade-invisibilidade" e "precaução-situações de risco" para o desenvolvimento de sistemas produtivos e de consumo saudáveis, com a efetiva preservação da integralidade da saúde e dos ecossistemas.

No entanto, o que vemos de forma corrente é a redução da biossegurança e da biosseguridade ao cumprimento de um receituário de "avaliação de risco" como uma parafernália normativa. No meu entendimento, trata-se de uma metonímica maquininha de contenção às críticas e às resistências diante dos perigos de certos inventos tecnológicos que se insere na perspectiva de atendimento aos interesses de mercado, induzindo o consumo de novas tecnologias além do razoável para a qualidade de vida. Ou de manipulação de agentes biológicos, químicos e físicos perigosos.

As técnicas de análise de risco foram sofrendo sofisticação matemática para produzir cientificidade e aumentar sua verossimilhança, mas que de fato não produzem na prática as medidas que garantam o não efeito negativo dessas tecnologias sobre a saúde e a qualidade da vida.

Uma experiência emblemática de atuação no campo específico da biossegurança que vivenciei ilustra bem esse entendimento. Por um período de 18 meses tive a oportunidade de ser membro titular da Comissão Técnica Nacional de Biossegurança CTNBio (2005-2007). De todos os espaços coletivos que atuei como sanitarista, em trinta e cinco anos de profissão, este foi sem dúvida o mais conflituoso, uma vez que está em jogo principalmente a legalização da produção e comercialização de alimentos transgênicos ${ }^{2}$. Embora diante da incerteza inerente aos processos biológicos relacionados com a transgenia, que obrigaria a aplicação do princípio da precaução, pude assistir a um modo de lidar com ela de forma absurdamente arrogante e pretensiosa, que se resumia em negá-la, claro, tudo para atender o apetitoso mercado do agronegócio. Nega-se a incerteza e coloca-se em seu lugar a crença na causalidade linear, ocultando que a produção de OGM na verdade utiliza uma técnica pelo acaso, só que realizada dentro de um laboratório.

Os "riscos" são enquadrados em parâmetros esquecendo-se de que são abstrações matemáticas $^{3}$. Acabam sendo coisificados e tratados como entes reais e passíveis de controle.

A invisibilidade da situação de risco provocado pelas tecnologias antigas e novas ou por agentes naturais ou artificiais de naturezas diversas é a grande preocupação da autora, que coloca a necessidade da biossegurança como uma ferramenta para visibilizar as situações de perigo a que os sujeitos humanos, individual e coletivamente são colocados, e também fundamental para a tomada de decisões amplamente esclarecidas.

Para a perspectiva colocada pela autora, é preciso um outro marco conceitual e metodológico

${ }^{1}$ Faculdade de Ciências Médicas, Universidade de Pernambuco (UPE). giraldo@cpqam.fiocruz.br 
para atuar de forma sistêmica sobre os contextos e os processos geradores de nocividades e que são matérias da Biossegurança e Biosseguridade.

A proposta é de uma biossegurança estruturada a luz de saberes compartilhados, que se colocam a disposição da proteção da saúde e do ambiente que desafia a saúde pública.

Não há nesta consideração um posicionamento antidesenvolvimento tecnológico, ao contrário, é o requerimento de um caráter humano para ele, única razão que deveria guiar os sistemas de ciência e tecnologia e as políticas públicas.

\section{Conclusão}

A precaução é um axioma para a construção da biossegurança e da biosseguridade e não a avaliação de risco. Corroborando com as autoras, algumas perguntas se colocam para garantir a biossegurança e a bisseguridade na perspectiva ética e da bioproteção: há suficiente conhecimento sobre as inter-relações entre uma dada tecnologia e as dinâmicas bio-sócio-ambientais? Como proteger efetivamente a vida diante de uma dada tecnologia ou de manipulações de agentes naturais ou artificiais que implicam em perigo para a saúde e para o ambiente? Há possibilidade de reversão de possíveis danos? Quem paga essa conta? As variabilidades biológicas estão sendo consideradas nessas ameaças e nas medidas de proteção? Quem ficará de fora? Aceitamos a exclusão de elementos da natureza, de classes sociais, de segmentos étnicos, de faixas etárias, de gênero, de susceptibilidades individuais ou hereditárias nessas medidas? Aceitamos ser transformados em "homens médios"? Em que medida a falta de políticas adequadas de biossegurança e biosseguridade afetam a soberania da população? Como informar e comunicar essas situações de perigo para uma ação esclarecida e responsável?

\section{Referências}

1. Guattari, F. As três Ecologias. $21^{\mathrm{a}}$ ed. Campinas: Ed. Papirus; 2011.

2. Augusto LGS. Carta da médica sanitarista e especialista em meio ambiente Lia Giraldo pedindo desligamento da CTNBio. In: Smith J. Roleta Genética. São Paulo: Ed. João de Barro; 2009. p. 1-3.

3. Lieber RR. Teoria e metateoria na investigação da causalidade [tese]. São Paulo (SP): Universidade de São Paulo (USP); 1998.

\section{Biossegurança, saúde, ambiente e comunicação de riscos: um debate necessário}

Biosafety, health, environment and risk communication: a necessary debate

Frederico Peres ${ }^{2}$

O artigo de Rocha e colaboradores, intitulado Biossegurança, Proteção Ambiental e Saúde: compondo o mosaico, trata de um tema da mais alta relevância e atualidade para a Saúde Coletiva: a construção do campo da biossegurança no país e de alguns marcos históricos e regulatórios relacionados. Coloca, com objetividade, a questão da biossegurança no âmbito do processo global de desenvolvimento, desde as formas através das quais o homem se apropria dos recursos naturais e transforma a natureza (causando diversos desequilíbrios que compõem parte significativa do objeto de estudo da biossegurança) até os diferentes padrões de produção e consumo observados ao redor do planeta.

Mas, para minha frustração (e, certamente, de muitos leitores desse bem-redigido artigo), deixa de apresentar uma análise crítica do processo de construção desse mosaico no país, que reúne fragmentos de questões ambientais, políticas, sociais, de desenvolvimento tecnológico e da saúde. Principalmente, quando consideramos a atualidade de tópicos como o uso da manipulação genética nos processos de produção agropecuária e a consequente preocupação pública acerca da ingestão de alimentos (em algum grau) geneticamente modificados. Assim, minha opção aqui, nesse debate, é colocar no foco do problema, de uma forma bem pontual, a necessidade de uma ampla e crítica discussão sobre as relações entre biossegurança, saúde e ambiente e, em última análise, o papel da comunicação (e da comunicação de riscos) na criação de um conhecimento público sobre biotecnologias e biossegurança. Espero, assim, contribuir com mais alguns fragmentos para a construção desse mosaico.

Tomemos como exemplo o processo que resultou na publicação da Lei 11.105 de 24 de Março de 2005 que dispõe, em âmbito nacional, sobre as questões relacionadas à biossegurança. Apesar de ter tra- 